\title{
The Use of Renewable Materials in Interior Design
}

\author{
Jiangyong Li \\ Environmental Art Design, Hebei Institute of Fine Arts, XinLe, Shijiazhuang, 050700, China
}

Keywords: Domestic Design, Traditional materials, Renewable materials, Interior decoration materials

\begin{abstract}
At present, the research and application on material still stays in the primary stage in domestic, mainly by introducing the foreign advanced technology and experience, rare in independent research and new materials development of technology. Proceeding from our national conditions, we should focus on the materials which is resource conservation and economic. In recent years, when continuously develop the new materials, they do not forget to grasp of environmental protection at the same time abroad, a large number of energy conservation and environmental protection green harmless material has been created. Because of the boomy of China's real estate, decoration has become the most popular topic in people's life, according to the statistics, decoration output value exceed more than 300 billion yuan a year. Due to heavy pollution and poor effect, the previous materials already can't satisfy people's needs .New material has good performance and decorative effect, what is important is the character of green environmental protection, and it become the new hot consumption.
\end{abstract}

\section{The Characteristics And Development Of New Materials}

New decorative material is safe and environmental protection, has the advantages of superior performance, easy operation, low cost, predominant than other material. Supported by a great number of developers and consumers.

Materials for exterior wall decoration. Decoration for Exterior wall is an important content of building decoration, materials for outer wall decoration generally have strong practicability. His purpose is to improve the ability to resist the attacking damage various nature factors such as dust, rain and snow, and freezing, and satisfy the function required such as heat insulation, sound insulation, waterproof, beautify, etc, with wall structure together. Common exterior wall decoration materials include: exterior wall coating: coating is refers to the material which can float on the surface and form tough protective film. Architectural coatings is an economic, simple construction, short time, high efficiency building decoration material, which adornment effect is good, easy maintenance. Ceramic decoration materials: ceramic wall is durable, colorful and has rich decorative effect, and easy to clean, fireproof, water resistance and abrasion resistance. The most important advantages is of corrosion resistance and low maintenance cost. The stone including natural veneer stone and artificial stone (marble, granite), the effect of natural veneer stone for adornment is good, durable, but the cost is expensive. Artificial stone has a light weight, high strength, corrosion resistance, low price, convenient construction.

Interior decoration materials. Interior wall decoration is a part of interior decoration. It can take both requirement of using and protecting structure into account. There have the Commonly used interior wall decoration materials: interior wall coating: various, colorful, fantastic effect . Facing stone: natural facing stone marble, is used for interior wall decoration mostly. And artificial veneer (artificial marble, prefabricated water tablets) is widely used in interior decoration too. Glazed tile: common glazed tile are white, color, printing color, color Mosaic and color murals, glazed tile has the character of surface smooth, beautiful, easy to clean, water resistance, waterproof. Interior wall decoration panel: there has plastic panel, fiber board, metal panels, plywood veneer, etc. 


\section{The Ground Adornment Material}

Ground adornment material should be security (refer to the stability and safety such as flame retardant, slip resistance, electric insulation, etc.), durable, comfortable (refers to the elastic when walking, sound insulation and sound-absorbing, etc.), decorative. The commonly used Decorative material has the following several kinds.

The wood floor. It is a kind of traditional ground material. Wood floor is simple and concise, comfortable, elastic walking, beautiful, expensive. Which is a kind of more advanced ground decorates material.

Stone. Stone floor mainly refers to natural marble and granite. They are elegant and luxuriant, adornment effect is good, but the price is expensive, it is a kind of advanced ground decorates material.

Ceramic tile. Ceramic floor tile durable, colorful, easy to clean, fire prevention, corrosion resistance, so the application is very extensive.

Plastic floor. Compared with paint, carpet, plastic floor usability is better, adaptation is strong, corrosion resistance, comfortable walking, adornment effect is good, and the price is moderate.

If we want to achieve the target of updating architectural for via the change of material, we need to have a clear understanding of the material itself. It's like we must be familiar with the vocabulary before writing. We know more about traditional materials because of the mature processing and construction craft, but for new building materials, people know less relatively. The limitations awareness about new material greatly hinder the implementation of the designers.

From the actual status of $t$ architectural design in domestic, due to awareness lacking of material, there often appear follow trend phenomenon, brick, glass curtain, sheet metal, had been used in same trend form on the building materials. Caused the public's visual fatigue and disgust eventually. For this reason, we should also do more investigation, familiar with the development of new materials and features.

There have profound theoretical system for each research and development for new material. Of course we don't need to get fully understand about its principle and production process ,but what we should get comprehend is the character about the material, construct, suitable for which object and serviceable range, etc. In addition to learning the new material, we can still continue to exploit their features and performance of the traditional material, by varying structure to achieve innovation.

\section{The Exterior Wall Coating}

Coating is the liquid material generally refers to the composition of adhesive, coating liquid of additives and pigment directly connected with the object surface. Application of coating is very extensive, often used for building external walls, floor, ceiling, roof waterproofing, etc. The biggest characteristic of exterior wall coating is that it can well reflect the variation of the building blocks, can create the seamless effect in widespread. At the same time it can provide us with the abundant optional colors, the cost and construction technical requirements are relatively low. Because itself doesn't provide too much visual details, when take that in design, we should be deliberate about the block combination, color contrast.

In the design, you can use a single color of paint and also use a variety of color combinations, single white coating can reduce the visual component of the outer wall material, purify the visual, can produce the feeling of pure and elegant aesthetic. White as the background, it can set out the details of the surroundings really. A large area of black can present a deep, mysterious visual effect, Because the contrast for light and dark is weak, usually it can hide some deficient details. Black used in large should pay attention to avoid the atmosphere of dreary and depressing. We can through the transparent glass material , local bright way to transfigure. A large area of grey paint can create soft artistic visual effect between white and black. Different color coating can create abundant visual effect. Many design success by the combination of the building blocks, coating 
colorific.

Water concrete. Concrete construction has caused the attention of people since the $1920 \mathrm{~s}$, and there have been a number of outstanding architectural works vividly in front of the world. Concrete has been architects play and taste, but its application in the interior design has not been the attention they deserve. From the point of the concrete in the construction of water construction, combining with the relevant requirements and characteristics of the interior design and construction of, respectively, from the space, function, quality performance and related technology are discussed in aspects of design key points of concrete in interior design; In concrete construction procedures, respectively expounds the cast-in-place concrete and precast concrete construction procedures in the interior decoration and construction requirements; Put forward the concrete that should be paid attention to in construction after the completion of several subsequent protection measures.

Today, the water concrete is still a challenge to many architects. Concrete technology development of China's late, large concrete construction does not see more, lenovo group research base is the "China's first large area concrete architecture", the designer cognition Xie Jiang said that he had just in books, only after the hands-on practice, knew real concrete kind of charm by emitting outside introversion. It skin feeling let a person produce desire to touch, it can even feel it breathing pores in fine point, it's full of spiritual affinity is comparable to any other building materials.

At the same time also have architects and designers in trying to clear water concrete in the indoor performance, such as female architect Dafna Arnon, she believes that the nature of the building from space, light, indoor and outdoor contact and detail design, some tiny elements such as furniture, art combined with concrete, colour, wood, light, the scenery penetrated into every corner of the house and change with the seasons change. She think architecture is not only its appearance, but also in the building itself. Residential facade is both unique and spectacular, although the bare concrete, give a person a sense of alienation, she managed to in their homes to create warm and intimate atmosphere. The bare, however, is still coming from the building itself, and interior design is secondary to modify and shape of building, so the water concrete elements in interior design as a kind of material and applications, from design to construction there are some differences. Material is the continuous discovery and use of natural objects, and be able to design and manufacture of various objects. The author this tradition of concrete materials in the application of interior decoration has been with great interest. The author by himself in the case of interior decoration, design and construction practice, combining with the construction of concrete in construction specification requirements and acceptance criteria, from the design point, construction procedures, subsequent protection concrete elements in interior design is discussed the application of the method.

The boomy of water Concrete is the period of the modernism architecture flourished, purely functional, economic, construction technology, ascribe to the same concrete building form., lacking of details. The result would be different if take design into concrete. Natural and optional.

Since the 1970 s. Famous Japanese architect Tadao ando was well known for his distinctive lighting design, delicate and elegant detail, strong sense of collection, the profound eastern philosophy. Among his works, concrete has become its landmark building materials, his works often shows exquisite texture of mechanical processing, letting more designer rediscovering the endless charm of the concrete. Then there rise the "concrete" hot. At the same time, the abuse of industrialization stylized unification of glass curtain wall, stone, brick in building decoration also makes people have a rebellious attitude. Natural, simple design style has become goals that people pursuit of. So that concrete has some new markets.

Different design pursuit different use of concrete, some people pursuit exquisite, strive to express the feeling of elegance .Some pursuit the rough strength feeling, keeping the traces of construction, pay attention to the authenticity of the performance. Another is the combination for rough and exquisite, making the structure looks elegant from overall, but powerful and rugged from close.

Ceramic bricks. For the pursuit of traditional beautiful craft, and in addition, in order to meet the requirement about light and thin which represent modern decoration materials ,then the new material appeared. 
In our country, brick used for exterior wall often paste by artificial workers. The advantage is construct convenient, especially for the lower and rich region for human cost. The disadvantage is that they can't guarantee the brick paste craft, what's more, long time soaking by rain and ruin by winter freeze-thaw hide safety trouble. In Japan, the most common method is to place and pouring the brick on concrete structure beforehand, therefore, tile and brick joint is closely and not easy to fall off the back.. This construction craft demanding high technology .As in the recent years advocates the spirit of environmental protection and energy saving in domestic, there appear the way factory paste the external tile on insulation board. Then put the finished plate fixed on the wall. Most of the brick has good durability, self-cleaning, corrosion resistance, etc, at the same time the price is relatively cheap, so it is easy to find in domestic use ceramic bricks both inside and outside wall.

Anticorrosive wood materials. The advantage of lumber can give a person sense of natural warm, both feel better in look and feel. But its shortcoming is weather resistance, durability. Hard to maintenance. Therefore, we rarely find it's decorate as external material directly. However, the research and development of new materials handled this problem. Adopting preservative treatment of wood (vacuum pressure, atmospheric soaking, spraying method), prolong the service life of its use in the outdoor environment, combined with the reasonable use and maintenance, ,some outdoor wood now can reach more than 20 years or 30 to 40 years of life.

Stone walls. Laying stones, the using of stone material just like laying brick masonry together, mainly through their weighing, generally applied in design for thicker wall which is not very high. We common lay pebble, not only aesthetically pleasing, and natural. At the same time also reflect a certain local cultural characteristics.

The common exterior wall material basically has the following kinds.

Exterior wall coating. It's common in life, cheaper prices than complex material, construction method is relatively simple. But the climate resistance, self-cleaning property is relatively poor. Water concrete: give the naturally feel on the visual sense, demand higher constructing technology, secondary construction needs to be done. For example, in order to improve the exterior clean, weather resistance and durability. Water brick, better visual effect, appearance more naturally, good in durability. However, maintenance cycle is long. Ceramic tile: the price is quite cheap, simple construction, durability, ideal self-cleaning . But the quality is hard to control, monitor, easy to fall off cuts. Stone wall facade: the price is high, the effect is good, self-cleaning, durable, weather resistance. Metal panel: price is high, effect is good, self-cleaning, durable. Wood (preservative): the price is higher, the effect is natural and pure, durable weather resistance and self-cleaning are general. Glass curtain: high price, durable weather resistance and self-cleaning is pretty good.

Vitreous brick. The price is higher, can create a special visual effect, hot weather resistance and self-cleaning property is better. The problem of poor thermal remains the same. U-shaped glass: the price is higher than glass curtain, special visual effect, durability, weather resistance, self-cleaning .But the thermal property is bad. Part of the roof material need to provide a good waterproof performance, so the request about durability, weather resistance is higher. In addition, designers should pay attention to the visual effect of the ground material about sensory effects. Concrete, cement material: the price is low, but easy to create dust, and is often used for low-grade building or a combination of floor coating. Terrazzo: look and feel good, can make it a variety of color and texture, excellent wear resistance. Floor coating: the price is cheaper, the color is abundant, and can be combined with transparent color coating concrete ground, used in primary processing such as terrazzo floor. Using Select for appropriate material push the development of architectural design to a new height. In general, designers should create works before study deep about each properties of material.

Modern society is highly productive society, as well as high consumption. How to limit resources constantly in the process of consumption, as far as possible to save resources, efficient used multiple times, maximum the value of resources? This is a worth further discussing issue for every field in modern society. Indoor decoration industry is widely regarded as a kind of high consumption of industry, popularize the use of renewable materials in the industry has a broader 
significance.

\section{The Definition Of Renewable Materials}

Material is the material basis for human survival and development and it is used to make into useful components, components or material of the item, but not all substance can be referred to as material. Waste materials made from raw materials, used as initial materials for producing semi-finished products, components and finished products in the design of the such as plastic, metal, leather, stone, wood, etc. The definition about material diverse in different field. The material quote from this article refers to materials which used for interior decoration design .The so-called "renewable" indicate reprocessing the old items, keep the original characteristics itself to become the new product. Renewable materials refers to the remaining material after manufacturing process, or found, removed from the waste materials from scrap . These renewable materials are harmless and can be recycled. Renewable materials does not include the electrical energy, wind energy and so on a series of energy which is renewable materials.

Compared with the traditional interior materials, renewable materials has the following characteristics: (1) the environmental protection; The application of renewable material avoid the secondary development of materials, and the pollution to the environment. And has carried on the strict health disinfection to waste material, has the good environmental protection. (2) Sustainability; Renewable materials can be recycled used. (3) Economic; Renewable materials may be legacy from decoration field, also may be thrown into the garbage. (4) The unique aesthetic; Renewable materials perhaps can achieve special adornment effect which traditional materials unable to do.

How to recycle renewable materials? Whether it will be "junk" after being used? That the recycle value account. In the form of "recycling" ,items ware sold flow in the secondary market, it not only prolong the service life of the goods, but also can increase the way of products and services. Another recycled form is known as the "rebirth", the component which constitute the old goods rebirth via reproduce a new goods. Through the craft processing ,the intrinsic characteristics of the waste materials make the change of its shape to form a new product, which continues to play a waste material again use value.

Like the life traveler, we always think that waste won't impressed people, always in a hurry to come and then in a hurry to disappear from life. But surprisingly, when we are faced with problem about serious environmental pollution and resources shortage, it has become a very important "friend" of our side, is like your shadow, cannot leave, otherwise, we will lose the whole earth!

After old stuff recycling, on the premise of guarantee quality, can use the old itself or unloaded parts from the old for secondary use, and can reform the parts which can not use directly to become the new furniture.

Industrial waste refers to all kinds of waste generated in industrial production, especially the construction waste. Today, with KunMing as an example, dismantle or reconstruct in the city will generate 38 million tons of construction waste. It is conceivable that city living space will be what appearance if the large amount of waste just throw away not handled in time, Therefore, we should actively the implementation of the construction waste in the utilization, it will reduce city waste pressure. There have report data that 1 tons of construction waste such as construction waste, such as debris, waste sand, concrete debris can be 0.45 tons of new wall material, the remaining $50 \%$ can be made into new road materials, $5 \%$ made of composite materials. At the same time, the garbage and other wastes should be classify in construction process, enterprises of renewable material recycling can prolong the life cycle of resources, avoid waste pollution maximum.

Since the industrial revolution, there generate big amount of waste by humans. According to data, about 3.1 billion tons of waste produced each year, of which 1.8 billion tons of garbage is non-toxic, 1.2 billion tons of civil garbage (living garbage and other debris), and 100 million tons of toxic waste. But life, construction, industrial waste recycling not only has economic value, and conducive to protect the environment. Nowadays, people have learned the extreme importance of material recycle, and waste recycling is becoming more and more popular, For artists, the use of waste is an inevitable choice, and they are also actively involved by the response, were held in the multiple 
renewable materials modification design contest both at home and abroad, and has found a creative way to convert the waste into human wealth. But still not mature, many design works in just waste the types of appearance design, unable to realize batch production.

At present, the domestic wastes are mixed garbage, all garbage waste is in a state of disorder. And the concept is similar like "dirty" ,"old" and "junk", therefore, in daily life, most people will ignore the old waste, get rid of it as "junk" directly, not to the consciousness of the recycling, it will affect the sustainable development of the human environment. In fact, we can see whether residential area or public places there are two trash cans and emissions in foreign countries, one is the recyclable bin, another is the unrecyclable bin. This method can categorizing waste. If we are to realize the importance of waste classification in recycling, perhaps we will never see garbage "a mountain" phenomenon.

"Waste" as useless waste in the world is not because it lost its function, but it left for its original site, temporarily abandoned. Puppet will find another new stage after leave the original occasions.

\section{Classification Of Renewable Materials}

With the development of interior decoration industry, renewable materials can be divided into: wood, cloth, paper, glass, plastic, metal.

Waste wood. Wood is the most familiar to people, one of the most widely used building decoration materials, it performance a decisive role in interior design. Due to the color of the wood with a pleasant and pleasing to the eye, elegant and beautiful texture, good tactility, stronger and ease for processing, so the wood is the choice of furniture and interior design since the ancient times. As is known to all, China is a country Lack of forest resources, spending a lot of money on importing lumber each year. At the same time, we generate a large amount of wood waste everyday, such a large energy consumption of wood become the very serious problem. Therefore, reutilization of waste wood also gradually improve for designers.

There are various kinds of wood used in indoor decoration, bamboo as the main raw material for furniture and interior decoration. Wood used most widely in the field of material, it is suitable for any indoor space, wall board, ceiling, doors and windows, the floor, furniture. At the same time, it also can use in indoor furniture decoration, the inspiration of the series of works which furniture brand MADE is from the daily life, every piece of furniture is to use old waste wood collected from Manhattan area and purely handmade, they are simple and practical, reflecting the style of New York City. In addition, waste wood also can be made for welcome sign when entering into a buliding, also can be the cylinder of the bar and so on.

From the above example, you can see that wood is an ancient and eternal decorative material, it has the incomparable characteristics with other material, also has a powerful function. it has beautiful texture and color. Both reusing wood and new material can match each other. On interior decoration design, waste wood selection, new model design, construction technology to improve, etc, have put forward new challenges to designers.

The waste fabric. Decorative fabric is the main content of interior decoration design, it's also the important means for decorative environment space, to strengthen the atmosphere for interior. It give a taste about elegant, grace, simple and other different feelings by its unique texture, which form quiet harmonious atmosphere indoor. It provide comfortable living environment as well as bring people spiritual life about beauty.

Different decorative fabric can represent different decoration styles, and decorative fabric has a different purpose in interior design, mainly can be divided into: sofa cover, curtain, bedding, carpet, cushion, table cloth and so on. Different fabric, according to its purpose, function, and the use of different texture (such as cotton, hemp, wool, chemical fiber, silk and other materials), through the different technical means such as processing, cutting, forming different specifications, different colors and textures, so as to achieve the different artistic effects, meet people's different expectations.

In the interior environment, any kind of fabric can affect the overall space design, and is likely to change the indoor atmosphere, in addition to use the fabric flexibility and controllability, we 
should keep the consistency of the whole atmosphere space. Therefore, in the choose matching decorative fabric for interior design, the selected textiles which from pattern, texture, color and material will be around a certain subject or the author according to some kind of feelings, in the other words ,that's to create a coordinated feeling with the design theme.

According to the consistency principle when doing fabric decorative for interior space, the utilization rate for the rest of the decoration fabric is very high. When choose the same or similar fabric, the abandoned fabric can make another accessories collocation, both economical and beautiful. A chimney made of cloth. When light through the different pattern of cloth, often turning into different light shadow, that means, you can t define light and shadow in your willing. if the waste fabric does not match the design style and the surrounding environment, you can put it in the dark.

With the concept of "light fixture, heavy decorate", decorative fabric is more and more popular in interior decoration design. It's a worthy pondering problem how to spend less cost under the condition of the noble, comfortable beautiful decoration space.

Waste paper. Invention, production and use of paper for human has been thousands of years, those papers we used can wrap the earth several times enough, due to the production of paper burn trees is more difficult to count. The development of society and the prosperity of culture will stimulate further demand for paper, coupled with the constantly matured industrialized production technology, the production efficiency of paper improved, so that continue to reduce production cost, the price of the paper is in the change. the packaging of goods form is more and more various, such as food, cosmetics, clothing, footwear, packaging cartons and other packaging materials. There has class of daily paper, such as disposable paper cups, boxes, all kinds of advertising and so on.

Most people don't think paper is very solid, it may not make it big or strong items. Actually this is wrong. Once I have seen two student of architecture, with the construction principle, they made big paper house, after the experiment proved that it can withstand wind, stand, rain resistance had struck. Paper is something we need all the time with the improvement of our living standard and has huge consumption. But it is often ignored by the us and discarded easily, at present there still have 6 million tons of waste paper in our country has not been recycled, waste paper recovery rate is only $20 \%$ to $20 \%$, which is equivalent to waste of forest resources 1 million -3 million acres, and $1 \mathrm{t}$ recycling waste paper can regenerate $800 \mathrm{~kg}$ of new paper, can save 17 big tree. Whether such a large number astonish us?

\section{Application of Renewable Materials in Interior Design}

Application in household accessories design elements of renewable materials. With the continuous development of social economy, people pay more and more attention to improve their quality of life, consumption concept has also transformed from the original conservative to consumption type. Living space environment requirements gradually improve, to meet their spiritual requirements, and highlight the personal taste and social status. This concept is constantly development of interior design industry .At the same time it also stimulated the people's life, the pursuit of fashion. But also promotes the innovation of design.

Any kind of decorate all need to polish by accessories. Home Furnishing accessories design is to decorate after the completion of the fixture, to make combination design for handicrafts, textiles, lamp decoration, flower art and so on, a second display of indoor and arrangements, thus forming a new concept. We can say it is the detail design for household decoration design, through the meticulously arrangement about details indoor to foil out high taste of decoration and unique design. "Light fixture, heavy adornment" concept is advanced without doubt, the idea act the role of accessories design on the interior design stage, to make people focus more attention to accessories.

Renewable materials used in the furniture. If indoor environment is an extension of the built environment, furniture is the ties connect interior space and human, in the progress of human civilization, people inseparable from the furniture. Furniture not only gives us convenient, but also gives us aesthetic feeling on the vision, can make us feel comfortable, warmth. Furniture design mainly around the "people-oriented" concept, present out the culture and mood. furniture in 
different interior space has different functions such as disjunctive space, create an atmosphere of space, adornment space and so on. Accord with the theme of the indoor environment, furniture meet people's spiritual needs and aesthetic requirements.

\section{Reference}

[1] Interior Decoration Materials, Cai Shaoxiang, Chemical Industry Press, 2010-9-1

[2] 21st Century Institutions of Higher Learning, Interior Decoration Materials and Construction, Chen Xuejie, China Electric Power Press, 2009-4-1

[3] Interior Decoration Materials and Construct tutorial, The National Higher Vocational Education of Art Design Professional, Zhangqian, Investigation Southwest Normal University Press, 2007-5-1

[4] Interior Decoration Materials in Colleges and Universities, Zhang Qqiumei, Xiang Shilong, Zhang Qiuhui, China Forestry Publishing House, 2003-4-1

[5] Interior Decoration Materials, Guo Hongwu, Water Conservancy and Hydropower Press, 2013-7-1

[6] The Construction of Interior Decoration Materials, Chen Xuejie, Industry Summit People's Posts and Telecommunications Publishing House 2013-6-1

[7] The Rural Residential Technology Based on Renewable Energy System Design Research, Liu Wenhe, China Building Industry Press, 2014-5-1 1

[8]Evaluation Standard about Renewable energy Construction Application Engineering (GB/T50801-2013), National Standards of the People's Republic of China

[9] Normal Remote Monitoring System Renewable Energy and Construction, Lian Xiaoqin. China Building Industry Press

[10] Renewable Energy and Building Energy Utilization Technology, Hao Xiaoli, China Building Industry Ppress, 2014-7-1

[11] Renewable Eenergy and Building Energy Efficiency Technology, Electric Power Press, 2012-1-1 